\title{
PELAKU PENGEMBANGAN BUDIDAYA TERNAK SAPI POTONG DI KABUPATEN SUKOHARJO PROVINSI JAWA TENGAH
}

\author{
K. I. Adinata ${ }^{1}$, Sunarso ${ }^{2}$ dan W. Sumekar ${ }^{2}$ \\ 1) Mahasiswa Fakultas Peternakan Dan Pertanian Universitas Diponegoro \\ Kampus drh. Soejono Koesoemowardojo Tembalang Semarang 50275 \\ E-mail: kharismaimama@gmail.com \\ ${ }^{2)}$ Fakultas Peternakan dan Pertanian, Universitas Diponegoro \\ Kampus drh. R. Soejono Kusumowardojo Tembalang, Semarang 50275
}

Diterima: 15 Juni 2016

Disetujui: 27 Oktober 2016

\begin{abstract}
ABSTRAK
Penelitian bertujuan untuk mengkaji peranan pelaku pengembangan budidaya ternak sapi potong di Kabupaten Sukoharjo Provinsi Jawa Tengah. Analisis peran pelaku pengembangan ternak sapi potong di Kabupaten Sukoharjo dianalisis dengan menggunakan metode analisis peran. Responden yang digunakan dalam penelitian ini adalah pihak-pihak yang terkait dalam pengembangan budidaya ternak sapi potong di Kabupaten Sukoharjo, terdiri dari kelompok tani ternak (KTT) di Kabupaten Sukoharjo, pihak Dinas Pertanian dan Peternakan Kabupaten Sukoharjo, pihak perbankan yaitu Bank BRI sebagai penyedia skim kredit pemodalan pengembangan budidaya ternak sapi potong di Kabupaten Sukoharjo. Alat bantu yang digunakan adalah kuesioner terbuka. Penelitian ini menggunakan metode penelitian survei dengan menggunakan data primer dan sekunder. Metode analisis data yang digunakan adalah analisis deskriptif. Hasil dari penelitian menunjukkan bahwa peran pemangku kepentingan dalam usaha ternak sapi potong telah dilaksanakan sesuai dengan role prescription, akan tetapi yang telah sesuai expectation adalah peran KTT dalam menjual dan memasarkan ternak sapi potong, dan peran Dinas Pertanian dalam pencegahan dan penanggulangan penyakit ternak
\end{abstract}

Kata Kunci: Analisis Peran, Pengembangan, Budidaya Ternak Sapi Potong

\section{ROLE CAST OF CATTLE DEVELOPMENT IN SUKOHARJO REGENCY CENTRAL JAVA PROVINCE}

\begin{abstract}
The purpose of this research is to determine the role cast development cattle in Sukoharjo Regency Central Java Province. Role analysis with cattle development in Sukoharjo Regency was analyzed with role analysis method. Respondent used in this research credit of who concerned in the development cattle in Sukoharjo Regency, such as follow with farmer group in Sukoharjo Regency, official agriculture and animal husbandry Sukoharjo Regency, Government Bank (BRI) as provider of credit skim capital to cattle development in Sukoharjo Regency. Instrument assist use open kuesioner. This Research use survei methodology for collecting primary and secondary data. Data collected was analyzed by deskriptive method. The Result, of this research showed that functionary
\end{abstract}


concerned in cattle development in term of cattle development Sukoharjo Regency already carried on appropriate role prescription, but then what did appropriate with expectation is role farmer group in selling and marketing beef cattle, and agriculture official to prevent and tackling animal disease.

Keywords : Role analysis, development, beef cattle

\section{PENDAHULUAN}

Pengembangan sektor pertanian dan peternakan merupakan salah satu tulang punggung pembangunan nasional dan implementasinya harus sinergis dengan pembangunan bidang sektor yang lainnya. Pelaku pengembangan sektor pertanian termasuk subsektor peternakan meliputi departemen teknis terkait, pemerintah daerah, petani/peternak, pihak swasta, masyarakat, dan pemangku kepentingan (stakeholders) lainnya. Koordinasi di antara pelaku pembangunan pertanian merupakan kerangka penting yang harus diwujudkan guna mencapai sebuah tujuan dan sasaran yang yang telah ditetapkan. Tujuan pengembangan sektor pertanian dan peternakan adalah: 1) membangun sumber daya manusia pertanian yang profesional, petani/peternak yang mandiri, dan kelembagaan pertanian dan peternakan yang kokoh, 2) meningkatkan pemanfaatan sumber daya pertanian secara berkesinambungan, 3) memantapkan ketahanan dan keamanan pangan, 4) meningkatkan daya saing dan nilai tambah produk pertanian dan peternakan, 5) menumbuh kembangkan usaha pertanian dan peternakan yang dapat memacu aktivitas ekonomi di daerah pedesaan, dan 6) membangun sistem ketatalaksanaan pembangunan pertanian yang berpihak kepada petani/peternak. Sementara itu, sasaran pembangunan pertanian yaitu: 1) terwujudnya sistem pertanian industrial yang memiliki daya saing dan ekonomi, 2) memantapkan ketahanan dan kedaulatan pangan secara mandiri, 3) terciptanya lapangan kerja bagi masyarakat pertanian/peternakan, dan 4) terhapusnya kemiskinan di sektor pertanian serta peningkatan pendapatan dan kesejahteraan petani/peternak (Departemen Pertanian, 2004).

Pengembangan pertanian secara keseluruhan meliputi program intensifikasi, rehabilitasi, sampai pada tahap diversifikasi dan salah satu subsektor pertanian yang mendapatkan prioritas utama pengembangan adalah peternakan dan perikanan (Saragih, 2001). Subsektor peternakan khususnya ternak sapi potong adalah salah satu sumber pertumbuhan ekonomi baik secara regional dan nasional (Syahrani, 2001). Oleh karena itu, pemerintah Republik Indonesia sangat menaruh perhatian besar guna meningkatkan intensitas produksi subsektor ternak sapi potong (King, 2007).

Hubungan keterkaitan antara satu pihak dan lainnya dapat berupa hubungan profit maupun non profit. Himpunan pelaku, keterkaitan dan peranan proses dalam pengembangan sektor ternak sapi potong menjadikan hal tersebut dapat dipandang sebagai suatu "sistem" (kesatuan). Untuk itu diperlukan informasiinformasi terkait dengan peranan dalam pengembangan sektor peternakan sapi potong di Jawa Tengah, khususnya di Kabupaten Sukoharjo. Penelitian bertujuan untuk melakukan kajian analisis peranan pengembangan budidaya ternak sapi potong di Kabupaten Sukoharjo.

\section{MATERI DAN METODE Pendekatan Penelitian}

Penelitian ini dilaksanakan pada bulan Desember 2014-Januari 2015 di Kabupaten Sukoharjo, Provinsi Jawa Tengah. Wawancara langsung dengan daftar kuesioner yang telah dipersiapkan elemen key informan yang mempunyai kompetensi yaitu Kepala Dinas Pertanian sebagai pemegang kebijakan, lembaga 
perbankan yang masih aktif menyalurkan kredit guna pengembangan ternak sapi potong di Kabupaten Sukoharjo yaitu Bank BRI, dan pengurus kelompok tani ternak sapi potong yang masih aktif serta memiliki jumlah anggota kelompok terbesar di tiaptiap kecamatan di Kabupaten Sukoharjo. Data sekunder (dokumentasi), yaitu pengumpulan data dan informasi dilakukan dengan cara menelaah, memahami, dan melakukan kajian dari sumber-sumber yang berkaitan dengan subsektor peternakan yang dirilis oleh Pemerintah Provinsi Jawa Tengah, Pemerintah Kabupaten Sukoharjo. Pengukuran data penelitian pada masingmasing peranan pendukung dianalisis secara deskriptif.

\section{Analisis Data}

Data yang diperoleh dianalisis menggunakan prosedur Analisis Peran dalam pengembangan agribisnis ternak sapi potong.

Analisis peran memiliki tiga komponen dasar yaitu, role prescription, role description, dan role expectation. Role prescription adalah sesuatu yang harus dilakukan. Role description adalah sesuatu yang terjadi atau telah dilakukan. Role expectation adalah sesuatu yang diharapkan dari pelaksanaan role prescription (Mayfield, 2006).

Teknik pengambilan data adalah dengan wawancara mendalam dengan elemen key informan yang mempunyai kompetensi, sarat informasi, dan disesuaikan dan diklarifikasi dengan pemangku kepentingan pengembangan ternak sapi potong, yaitu aparatur dari Dinas Pertanian dan Peternakan, lembaga perbankan, dan pengurus kelompok ternak sapi potong yang masih aktif serta memiliki jumlah anggota kelompok terbesar di tiaptiap kecamatan di Kabupaten Sukoharjo.

\section{HASIL DAN PEMBAHASAN Karakteristik Responden Kelompok Tani Ternak \\ Karakteristik Responden Pengurus} Kelompok Tani Ternak Berdasarkan hasil survei yang telah dilakukan, ditunjukkan pada Tabel 1 .

Tabel 1. Karakteristik Pengurus KTT di Kabupaten Sukoharjo Tahun 2015.

\begin{tabular}{lcc}
\hline Karakteristik & Jumlah (Orang) & Persentase (\%) \\
\hline Umur (tahun) & 7 & 19,4 \\
$30-40$ tahun & 10 & 27,7 \\
$41-50$ tahun & 9 & 25 \\
$51-60$ tahun & 7 & 19,4 \\
$61-70$ tahun & 3 & 8,3 \\
$>71$ tahun & & \\
Pendidikan Formal & 4 & 11,1 \\
Tidak Sekolah & 8 & 22,2 \\
SD & 6 & 16,66 \\
SMP & 15 & 41,6 \\
SMA & 3 & 8,3 \\
Perguruan Tinggi & & \\
Pekerjaan Pokok & 7 & 19,4 \\
Petani & 6 & 16,6 \\
Buruh Tani & 9 & 25 \\
Wiraswasta & 5 & 13,8 \\
Swasta & 3 & 8,3 \\
Buruh & 6 & 16,6 \\
Lainnya & & \\
Pengalaman Beternak & 7 & 19,44 \\
$<5$ tahun & 10 & 27,77 \\
5-15 tahun & 19 & 52,77 \\
$>15$ tahun & & \\
\hline \hline
\end{tabular}

Sumber: Analisis data primer, terolah 2015. 
Hasil survei menunjukkan bahwa mayoritas responden pengurus KTT berada pada kisaran umur yang produktif, yaitu 4150 tahun atau $27,7 \%$ dari persentase total sampel responden. Umur produktif berkisar antara umur 15 sampai 64 tahun,sedangkan umur dibawah 15 tahun dan diatas 64 tahun termasuk dalam umur non produktif (Tarmidi, 1992). Pada umur produktif tenaga yang digunakan masih prima sehingga mampu mengembangkan usahanya dan ada kemungkinan menambah pengetahuan serta metode budidaya di bidang usaha ternak sapi potong.

Mayoritas responden peternak berpendidikan SMA sebesar 41,6\%. Peternak yang berpendidikan rendah biasanya lebih sulit menerima inovasi teknologi baru yang berkaitan dengan usaha ternak, dan cenderung menekuni apa yang biasa dilakukan oleh nenek moyangnya secara turun temurun (Wirdahayati, 2010). Pekerjaan pokok responden peternak sapi potong di Kabupaten Sukoharjo, adalah $48 \%$ bekerja sebagai petani dan buruh tani dan sisanya bekerja di berbagai bidang. Menurut pernyataan Soeharsono et al. (2010), hal ini merupakan gambaran umum penduduk yang tinggal di kawasan pedesaan, dimana sebagian besar mengandalkan mata pencaharian mereka pada bidang pertanian dan didukung oleh sub sektor peternakan.

Pengalaman peternak dalam melaksanakan usaha budidaya ternak sapi potong adalah rata-rata adalah lebih dari 15 tahun. Soeharsono et al. (2010) mengemukakan bahwa semakin lama pengalaman peternak membudidayakan ternak sapi potong, memungkinkan mereka untuk lebih banyak belajar dari pengalaman, sehingga dapat dengan mudah menerima inovasi teknologi yang berkaitan dengan usaha ternak sapi potong menuju perubahan baik secara individu maupun kelompok.

\section{ANALISIS PERAN}

Peran pemangku kepentingan dalam pengembangan ternak sapi potong di Kabupaten Sukoharjo sangat penting bagi pengembangan bidang ternak sapi potong di provinsi Jawa Tengah. Sesuai deskripsi dan harapan terhadap peran masing masing stakeholder menjadikan suatu kekuatan yang mendukung terjalinnya rantai simbiosis dalam sebuah hubungan pengembangan ternak sapi potong serta eksistensi dari para stakeholder. Evaluasi peran dilakukan pada beberapa pemangku kepentingan yaitu Kelompok Tani Ternak Sapi potong, Bank BRI, Dinas Pertanian Kabupaten Sukoharjo.

\section{Peran Kelompok Tani Ternak Sapi Potong}

Kelompok tani ternak ikut berperan serta dalam pengembangan ternak sapi potong di Kabupaten Sukoharjo pada khususnya dan Provinsi Jawa Tengah pada umumnya. Peranan KTT adalah memberi pembinaan kepada anggotanya.

Kelompok tani ternak adalah suatu unit yang terdapat beberapa individu, yang mempunyai kemampuan dan tujuan yang sama, untuk berbuat dengan kesatuannya dengan cara dan atas dasar kesatuan persepsi khususnya di bidang budidaya sapi potong. Kelompok tani berfungsi sebagai wadah dalam pengembangan kemampuan anggota kelompok atau peternak dalam pemenuhan akan kebutuhan daging di masyarakat, baik itu daging ternak besar berupa sapi, kambing, kerbau ataupun juga daging unggas seperti ayam, itik dan bebek. Kebutuhan ini menjadi prospek yang baik bagi pengembangan ternak dengan sistem berkelompok. Sistem berkelompok 
diarahkan agar setiap anggota berperan menjalankan tugas dan fungsi yang telah aktif dalam pengembangan kelompok dan ditetapkan.

Tabel 2. Peran Kelompok Tani Ternak Sapi Potong

\begin{tabular}{llll}
\hline \hline No & Prescription & Description & Expectation \\
\hline 1 & Menjual dan memasarkan ternak sapi potong & Sudah dijalankan & Sudah sesuai \\
2 & Melakukan pembinaan kepada anggota kelompok & Sudah dijalankan & Belum sesuai \\
\hline
\end{tabular}

Sumber: Data primer, 2015.

KTT telah menjalankan perannya dalam membeli dan memasarkan ternak sapi potong untuk kesejahteraan KTT tersebut, dengan memberikan harga sesuai kualitas dan kuantitas ternak sapi potong sesuai standar harga di pasaran. Harapan yang diinginkan telah sesuai dengan prescription, akan tetapi peternak KTT menginginkan adanya kenaikan harga sapi potong di pasaran dan meminta kepada pemerintah untuk membatasi importasi sapi potong.

Pembinaan terhadap anggota KTT, telah dilakukan demi mendapat kuantitas dan kualitas ternak sapi potong yang baik guna meningkatkan kesejahteraan peternak anggota KTT. Expectation rate dari 12 KTT yang diwawancarai diketahui bahwa rata rata anggota KTT jarang mendapat materi pembinaan baik oleh instansi pemerintah maupun penyuluh swadaya lainnya sehingga teknologi bidang budidaya ternak sapi potong di Kabupaten Sukoharjo masih susah dimengerti dan diaplikasikan, sehingga banyak KTT agak kesulitan dalam menjaga keberlangsungan usaha ternak sapi potong.

Keberadaan kelompok tani ternak di Kabupaten Sukoharjo belum dimanfaatkan sebagaimana fungsinya. Perlu adanya pembinaan dari pemerintah daerah terkait agar kelompok tani ternak tersebut mampu bangkit sehingga keberadaannya mampu mengangkat kesejahteraan para anggotanya.

\section{Peran Perbankan}

Perbankan sebagai lembaga yang dapat berfungsi sebagai penyedia modal berperan dalam memberikan kredit pinjaman modal kepada pelaku usaha ternak sapi potong di Kabupaten Sukoharjo.

Tabel 3. Peran Perbankan

\begin{tabular}{|c|c|c|c|c|}
\hline No & Prescription & & Description & Expectation \\
\hline 1 & $\begin{array}{l}\text { Menyediakan } \\
\text { Modal }\end{array}$ & Pinjaman & Sudah Dijalankan & Belum Sesuai \\
\hline
\end{tabular}

Sumber : Analisis Data Primer, 2015.

Perbankan telah menjalankan perannya dalam menyediakan pinjaman modal bagi pelaku usaha di bidang ternak sapi potong (kelompok tani ternak sapi potong). Perbankan juga bekerja sama dengan pemerintah dan pemegang kebijakan dalam menyediakan pinjaman dengan bungan ringan kepada beberapa pihak yang concern dibidang peternakan sapi potong dengan memberikan kredit KKPE (Kredit Ketahanan Pangan dan Energi), dan KUPS (Kredit Usaha Pembibitan Sapi). Tabel 4 menjelaskan mengenai plafon kredit bagi KKPE. 
Tabel 4. Kebutuhan Kredit Penggemukan Sapi Potong

\begin{tabular}{lll}
\hline \hline No & Keterangan & Total Cost (Rp) \\
\hline 1 & Sapi Bakalan & 20.250 .000 \\
2 & Kandang & 500.000 \\
3 & Peralatan & 200.000 \\
4 & Pelayanan teknis & 300.000 \\
5 & Pakan & \\
& HMT & 900.000 \\
& Konsentrat & 2.750 .000 \\
6 & Lain-lain & 100.000 \\
\hline & Total & $25.000 .000,-$ \\
\hline
\end{tabular}

Sumber: Juklak KKPE BRI (2015).

Tabel 5. Kebutuhan Kredit Pembibitan Sapi

\begin{tabular}{lll}
\hline No & Keterangan & Total Cost (Rp) \\
\hline 1 & Induk Bunting & 20.000 .000 \\
2 & Konsentrat & 3.000 .000 \\
3 & Obat dan Operasional IB & 300.000 \\
4 & Kandang & 1.600 .000 \\
5 & Lain-lain & 100.000 \\
\hline & Total & $25.000 .000,-$ \\
\hline
\end{tabular}

Sumber: Juklak KKPE BRI (2015).

Pada Tabel 4 dan 5 menjelaskan plafon kredit KKPE bagi peternak sapi potong penggemukan maupun pembibitan dengan nilai plafon sebesar Rp 25.000.000,yang diperuntukkan bagi peternak maupun kelompok ternak di Kabupaten Sukoharjo yang memenuhi rekomendasi dan syarat dari dinas pertanian atau peternakan setempat dan lolos dari pemeriksaan dari bank BRI.

Dari hasil wawancara pihak KTT belum semuanya mengakses sarana pemodalan melalui bank BRI dan masih ragu dalam melakukan peminjaman modal dikarenakan tidak ingin terlalu repot dalam hal permodalan.

\section{Peran Dinas Pertanian Kabupaten Sukoharjo}

Dinas pertanian merupakan dinas teknis yang berperan dalam bidang peternakan sapi potong di Kabupaten Sukoharjo. Berikut ini analisa peran Dinas pertanian Kabupaten Sukoharjo dalam usaha mengembangkan ternak sapi potong.

Tabel 6. Peran Dinas Pertanian Kabupaten Sukoharjo.

\begin{tabular}{llll}
\hline \hline No & Prescription & Description & Expectation \\
\hline 1 & $\begin{array}{l}\text { Peningkatan kemampuan peternak } \\
\text { melalui KTT yang ada }\end{array}$ & Sudah dijalankan & Belum sesuai \\
2 & $\begin{array}{l}\text { Penerapan teknologi tepat guna untuk } \\
\text { pengembangan peternakan sapi potong }\end{array}$ & Sudah dijalankan & Belum sesuai \\
3 & $\begin{array}{l}\text { Pencegahan dan penanggulan penyakit } \\
\text { ternak }\end{array}$ & Sudah dijalankan & Sesuai \\
\hline
\end{tabular}

Sumber : Data Primer, 2015. 
Dinas pertanian memiliki peran meningkatkan kemampuan peternak, dengan cara melakukan pembinaan melalui semua KTT yang ada di kabupaten Sukoharjo. Hal tersebut telah dilakukan oleh Dinas Pertanian, yaitu melalui penyuluhan bidang peternakan yang ada dan juga bekerjasama dengan perguruan tinggi membina KTT.

Pembinaan yang dilakukan oleh dinas tidak rutin pada setiap KTT, banyaknya KTT dan terbatasnya jumlah tenaga penyuluh serta terbatasnya anggaran menyebabkan dalam satu tahun tidak semua KTT memperoleh pembinaan langsung dari dinas. Oleh karena itu, diharapkan dinas mampu mengatur lagi pembinaan yang rutin dan merata kepada peternak agar kemampuan peternak dalam melakukan usaha agribisnis sapi potong lebih meningkat sehingga populasi ternak sapi dan produksi daging daerah meningkat. Selain itu, petugas penyuluh peternakan sebaiknya adalah orang yang mampu dan memiliki kualifikasi sesuai dengan bidang penyuluhan yang diberikan.

Dinas pertanian Kabupaten Sukoharjo juga melakukan penerapan teknologi tepat guna demi pengembangan peternakan sapi potong. Salah satu penerapan teknologi yang dilakukan yaitu dengan mendirikan pos IB di tiap Kecamatan Di Kabupaten Sukoharjo. Pendirian pos IB tersebut akan memudahkan peternak peternak sapi potong yang akan mengawinkan sapi betinanya yang sedang estrus, sehingga tidak perlu jauh-jauh untuk mencari inseminator.

Pencegahan dan penanggulangan penyakit dilakukan dengan adanya pelayanan kesehatan bagi ternak. Vaksinasi juga dilakukan untuk mencegah terjangkitnya ternak sapi potong akan penyakit menular yang berbahaya. Pelaksanaan vaksinasi dan pelayanan kesehatan yang ada ini diharapkan lebih merata, karena belum semua peternak merasakan manfaat fasilitas ini.

\section{SIMPULAN DAN SARAN}

\section{Simpulan}

Berdasarkan hasil penelitian, menunjukkan bahwa peran pemangku kepentingan di Kabupaten Sukoharjo dalam mengembangkan usaha budidaya ternak sapi potong telah dilaksanakan sesuai dengan role prescription, akan tetapi yang telah sesuai expectation adalah peran KTT dalam menjual dan memasarkan ternak sapi potong, dan peran Dinas Pertanian dalam pencegahan dan penanggulangan penyakit ternak

\section{Saran}

Memperkuat kelembagaan peternak di kabupaten Sukoharjo sehingga peternak mempunyai dan memiliki daya tawar yang kuat dalam hal pembudidayaan dan pemasaran ternak sapi potong.

\section{DAFTAR PUSTAKA}

Departemen Pertanian. 2004. Strategi dan Kebijakan Pembangunan Pertanian. Departemen Pertanian, Jakarta.

Dinas Pertanian Kabupaten Sukoharjo. 2015. Sukoharjo dalam Angka. Dispertan data Statistik Sukoharjo.

King, G. 2007. Livestock in the future. Animal Sciences 6:109-130.

KKPE dan KUPS BRI. 2015. Petunjuk

Pelaksanaan Kredit Ketahanan

Pangan dan Energi Peternakan. Bank BRI. Jakarta.

Mayfield. J.L. 2009. Studying Role Expectation. Today Speech. Volume 15. 
Saragih B. 1997. Tantangan dan Strategi

Pengembangan Agribisnis

Indonesia. Jurnal Agribisnis 1 (2):

16-28.

Soeharsono, R. A. Saptati dan K. Diwyanto.

2010. Kinerja Reproduksi Sapi

Potong Lokal dan Sapi Persilangan

Hasil Inseminasi Buatan di Daerah

Istimewa Yogyakarta. Prosiding.

Seminar Nasional Teknologi

Peternakan dan Veteriner. Bogor

3-4 Agustus 2010. Pusat Penelitian

dan Pengembangan Peternakan,

Bogor. hal 89-99.

Syahrani. 2001. Penerapan Agropolitan dan

Agribisnis dalam Pembangunan

Daerah. Jurnal Frontir 33:1-11.

Tarmidi, L. T. 1996. Analisis Transportasi Wilayah . Kumpulan Materi Pelajaran Diklat Substansif Dinas PU Cipta Karya Bidang Penyusunan Rencana Tata Ruang Kabupaten di Lingkungan Pemerintahan Propinsi Dati I Jawa Barat. Tanggal 13 s/d 26 Oklober 1996, Bandung.

Wirdahayati, R. B. 2010. Kajian Kelayakan dan Adopsi Inovasi Teknologi Sapi Potong Mendukung Program PSDS: Kasus Jawa Timur dan Jawa Barat. Prosiding. Seminar Nasional dan Veteriner. Bogor 3-4 Agustus 2010. Pusat Penelitian dan Pengembangan Peternakan, Bogor. hal 339-346. 